\title{
Assessing Economic Losses of Lake Kaban (Kazan, Russia) Ecosystem and Developing of Compensation Measures within the Framework of Sports Facilities Construction
}

\author{
Derevenskaya 0. Yu. \\ Kazan Federal University, Institute of Management, Economics and Finance, Kazan, 420008, Russia
}

Mingazova N.M.

Kazan Federal University, Institute of Management, Economics and Finance, Kazan, 420008, Russia

Mingaliev R.R.

Kazan Federal University, Institute of Management, Economics and Finance, Kazan, 420008, Russia

Pavlova L.R.

Kazan Federal University, Institute of Management, Economics and Finance, Kazan, 420008, Russia

Email address: oderevenskaya@mail.ru

\section{Doi:10.5901/mjss.2014.v5n24p361}

\section{Abstract}

We have calculated the environmental losses arising in the course of preparation and construction activities on the lake Kaban. The size of environmental damage caused under construction was evaluated in a total of \$273,863 USA. Developed compensatory measures that reduce the effects of damage caused by the construction work. We have developed a concept of biological rehabilitation of the lake and we have made prediction of change in the state of the lake ecosystem as a result of rehabilitation measures.

Keywords: economic losses, assessment, lake, ecosystem, rehabilitation

\section{Introduction}

Construction of various facilities is a form of impact on the environment and usually leads to negative consequences causes' economic damage. Legislation of the Russian Federation is assumed assessment of environmental harm caused to the environment, natural resources, public health and reparation of damage $[8,9,10]$.

Kazan is the city of the Universiade - 2013. The projects of construction of sports facilities are developed and implemented during the preparation for this important international sports events, including the rowing canal [3]. Lake Middle Kaban on their morphometric parameters and conditions of the location of the lake is suitable to host the rowing course.

Kaban lake has oxbow-karst origin. The water surface area is 129.7 ha, volume - 11,156.2 $\mathrm{m}^{3}$, maximum depth $22.8 \mathrm{~m}$. Lake fed by groundwater, precipitation is receivers untreated waste water outlets stormwater and wastewater enterprises, first of all, the receiver-cooler heat-power stations of Kazan. Due to the pollution of the lake water, an essential part of the work on the design of a rowing race should make the development of environmental measures aimed at restoring the water quality of lake.

Construction and exploitation any sports facility must meet the requirements of the International Committee of Sports. They must also integrate harmoniously with the landscape and the city's infrastructure, as well as comply with environmental protection standards and requirements. The aim of this work was to assess the environmental damage caused by the implementation of the project and to develop compensation measures. 


\section{Method}

Construction work was carried out in the period of 2009-2013. The damage caused by the components of the environment consists of the following: damage from fish kills and loss of food organisms, loss of feeding areas; damage caused by felling of green trees; damage from soil contamination; damage from backfill and removal of wetland vegetation. The following are the formulas for the calculation of various types of damage.

Damage to fish resources consisting of: 1 ) the loss of the feeding areas of the reservoir and the complete loss of their fish production after filling part of the area as a result of straightening the shoreline and bank stabilization; 2) loss of food organisms from the effects of construction machinery alignment beaches, shore protection and temporary filling; 3 ) calculating the damage from the loss of habitat and reduce the reproduction of aquatic organisms by reducing the reproduction of forage fish as a result of filling part of the area [7].

Damage to fish resources from the loss of feeding areas calculated by the formula: $\quad N=P_{0}{ }^{*} S^{*} 10^{-3}$,

where $\mathrm{N}$ - the damage in tons, Po - pond fish productivity ( $\mathrm{kg} / \mathrm{ha}$ ), $\mathrm{S}$ - area of the water or its part, has lost its fishery value (n), 10-3 - a multiplier to convert kilograms to tons.

Calculate the volume compensation investments $(K)$ was calculated by the formula: $K=M * K_{0} * E_{n} * t * k_{i},(2)$

where $M$ - natural damage; En - regulatory cost-effectiveness ratio of capital investments; $K_{0}$ - specific capital investment; $t$ - time of the negative impact on fish stocks; $k_{i}$ - the coefficient of the deflator to convert prices to 1991 prices this year.

Assessment of damage to fisheries from destruction of food organisms was conducted by the formula:

$N_{1}=B * P / B$ * $1 / K 2$ * K3/100 * $S(V)$ * $k$ * $t_{0} / t_{1} * n,(3)$

where $\mathrm{N}_{1}$ - the damage in tons of fish products; $\mathrm{B}$ - average biomass of food organisms (phytoplankton, zooplankton, zoobenthos) in $\mathrm{mg} / \mathrm{m}^{3}\left(\mathrm{~g} / \mathrm{m}^{2}\right)$; P / B - coefficient to convert the biomass of food organisms in the product, $\mathrm{K} 2$ - feed conversion ratio to convert food organisms in fish products; K3 - an indicator of the maximum possible use of forage fish (\%); $\mathrm{S}(\mathrm{V})$ - area of the zone output, the dump, siltation (zone volume turbidity) in $\mathrm{m}^{2}\left(\mathrm{~m}^{3}\right), \mathrm{k}$ - the mortality rate of food organisms in the areas of impact dredgers, $\mathrm{t}_{0} / \mathrm{t}_{1}$ - time / open water period (206 days); $\mathrm{n}$ - factor to convert grams per tonne $(1 / 1000000)$.

To calculate the damage from the loss of aquatic habitat as a result of rectification of coastline used the same formula, but with different coefficients $(2,3)$.

Payment of compensation for damage caused during the degradation of soil and land, determined by the formula: $\mathrm{Y}=\mathrm{H}$ * Kp * $\mathrm{S}^{*} \mathrm{~K}_{4}{ }^{*} \mathrm{~K}_{5}$ * $\mathrm{K}_{6},(4)$

where: $Y$ - the size of penalties for harm (\$ USA); $\mathrm{H}$ - standard cost of land (\$ USA/ha); Kp - regional coefficient set for suburban areas of cities of republican subordination and the oil zone; $\mathrm{S}$ - area of degraded land (ha); $\mathrm{K}_{4}$ - the coefficient of the environmental situation $=1.9 ; \mathrm{K}_{5}$ - the coefficient of protection of land, taking into account the category of land and the type of vegetation cover; $\mathrm{K}_{6}$ - coefficient taking into account the degree of soil degradation [5].

Assessment of damage to woody vegetation was carried out according to the formula: $C_{1}=B_{1} j_{1}$ * $K_{7} * K_{8}$ * $U_{1}$, (5)

where: $C_{1}$ - the cost of the demolished tree (\$USA); $B_{1}$ - the base cost of the tree as defined by the rock and tree diameter (at $1.3 \mathrm{~m})(\$ \cup S A) ; j_{1}$ - a group of trees on their property; $\mathrm{K}_{7}$ - correction factor vital condition of green spaces; $\mathrm{K}_{8}$ - correction factor for the functional use of green spaces; $\boldsymbol{h}_{1}$ - the index change of the estimated cost $[4,5,6]$.

The cost of the demolished bush was determined by the formula:

$\mathrm{C}_{2}=\mathrm{B}_{2} \mathrm{j}_{2} * \mathrm{~K}_{7} * \mathrm{~K}_{8} * \mathrm{U}_{1} ;(6)$

$\mathrm{C}_{2}$ - the cost of the demolished bush (\$ USA) $\mathrm{B}_{2}$ - base cost bush, taking into account the specific breed and age (\$ USA); j2 - a group of trees by their value $[4,5,6]$. S; (7)

Damage from the backfill and removal of wetland vegetation was calculated by the formula: $C_{3}=B_{3}{ }^{*} K_{9}{ }^{*} K_{10}$ * $h_{1}$ *

where $C_{3}$ - the cost of the demolished lawn (\$ USA); $B_{3}$ - the base cost of the lawn (\$ USA); $K_{9}$ - correction factor vital condition of wetland vegetation; $\mathrm{K}_{10}$ - correction factor for the functional use of green spaces; $\mathrm{S}$ - area of the demolished pitch (wetland vegetation) $[4,5,6]$.

\section{Results}

\subsection{Assess the damage}

The construction project of the Center for rowing sports on Lake Kaban in Kazan was unique of its kind, unique in the 
country and world. However, the construction work will inevitably lead to increasing the impact on the ecosystem of the pond, environmental and economic damage. Not all types of damage can be assessed in monetary terms. So far, there are no approved methods for calculating damages from the loss of biodiversity, changes in habitat, reduce the potential of self-cleaning, etc. Consequently, predictive calculations of damage according to accepted and approved methods known to always lower than the actual damage to ecosystems.

The table 1 presents data on the assessment of the environmental damage caused during the construction of the Center rowing sports lake and surrounding area.

Table 1. Types of environmental damage and the estimate for the project of the Center rowing sports.

\begin{tabular}{|l|c|}
\hline Type of damage & Amount, \$ USA \\
\hline Fisheries damage & 21274 \\
\hline Damage to soils & 42616 \\
\hline Damage to trees and shrubs & 205745 \\
\hline - actual damage & 27884 \\
\hline - expected cost of disaster & 177861 \\
\hline Damage from the backfill and removal of wetland vegetation & 4227 \\
\hline Total & 273863 \\
\hline
\end{tabular}

Thus, the total expected cost of disaster of the construction of the Center for rowing sports and its infrastructure is estimated at 273,863 \$ USA. The greatest damage was trees and shrubs, from which actual damages amounted to 27,884 \$ and projected 177861 \$.

The safe water quality - one of the conditions for the creation of channels and international rowing distances. The project is currently hindered by the high degree of contamination of water and sediment of Lake Kaban. Therefore, we have developed a concept of biological rehabilitation of the lake.

\subsection{The concept of biological rehabilitation}

The main sources of pollution of Lake M. Kaban are: mass flow of stormwater runoff, leading to pollution and siltation of the lake; thermal and chemical pollution of the lake by sewage Kazan combined heat and power; pollution due to accidental discharges of enterprises and economic issues, fecal sewage; secondary contamination of sediments [1, 2].

The concept of biological rehabilitation offers a comprehensive approach to addressing the major challenges to improve water quality in the lake, consisting of three phases (Fig. 1).

The first stage includes the scientific, technical and hydrobiological studies of the lake ecosystem: the definition of the thickness of sediments and the degree of contamination; analysis of the quality of water flowing into the lake and sewage; assessment of the state of biological communities (phytoplankton, zooplankton, zoobenthos, fishes); assessment of higher aquatic vegetation of the lake and trees and shrubs in the area adjacent to the lake.

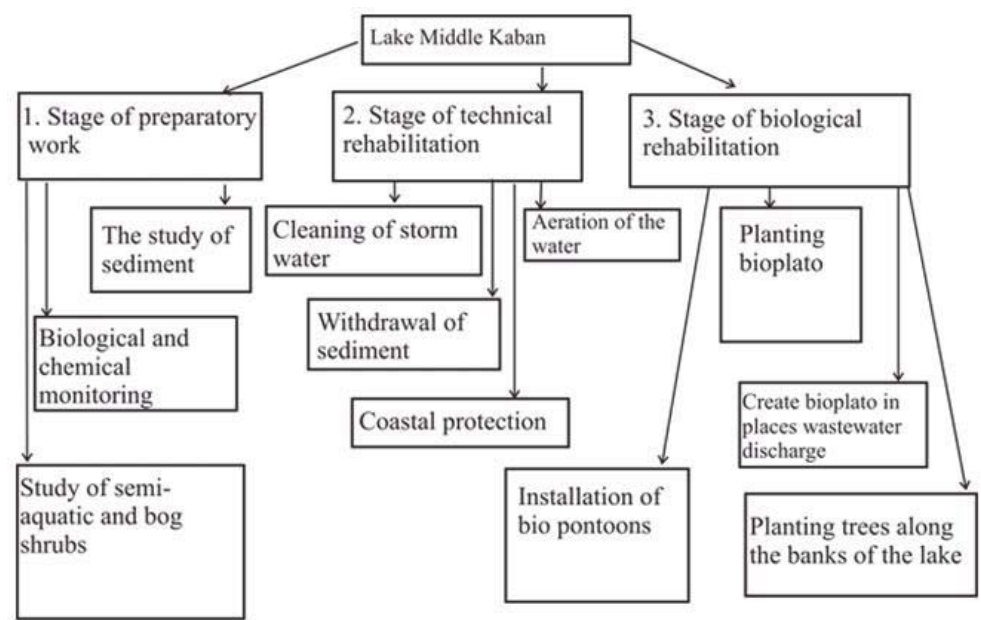

Fig. 1. The concept of biological rehabilitation of Lake M. Kaban. 
At the second stage the technical measures: withdrawal layer of polluted sediments, aeration bottom water layers, bank stabilization, installation of treatment facilities for stormwater issues.

For dredging sediment from the lake M. Kaban most suitable dredging method. Recommended the removal of sediment on an area of 70 hectares, a thickness of $2 \mathrm{~m}$, the total volume of $140,000 \mathrm{~m}^{3}$. In those areas where the removal of contaminated soil is not possible (or after the implementation of the work) recommended screening bottom powder sediment layer of clean sand, clay or sorbent material thickness of $15-30 \mathrm{~cm}$. Event is held to prevent the release of nutrients and pollutants from bottom sediments.

Aeration speeds up the oxidation processes, thereby helping to cleanse the body of water. For Lake M. Kaban minimum aeration is required in 4 places at once. For water aeration encouraged to use traditional aerators and oksidators (for winter).

For Lake M. Kaban major issues are: delivery of significant volumes of storm water, the use of the lake in the technological cycle heat and power plant of Kazan as a cooling pond plants, water pollution from industrial enterprises of the South industrial zone, delivery of emergency discharges of domestic and fecal sewage and municipal pollution from individual development of the private sector. At major releases stormwater treatment facilities offered to place stormwater. Engineering solution can be implemented by means of mechanical cleaning, using a drum-type installation microfiltration. These settings will operate in two modes - clean the incoming waste water during intense they become available, the rest of the water to clean the lake.

The third stage - the stage of biological rehabilitation. Along the coastal zone of Lake M. Kaban provides continuous system of landscaping to include sections of the existing vegetation.

For biological treatment of the lake, removal of nutrients, heavy metals and petroleum products are encouraged to use higher water vegetation (for a landing on pontoons and moving in the littoral part of the lake). Macrophytes can also be used for pre-treatment of water in the channel from the combined heat and power, which flows into the lake. Here alternate small plots (planted with vegetation that absorbs nutrients) and deep-sea areas (where the activity takes place aeration of water and deposition of pollutants).

\section{Conclusions}

Thus, the use of modern technology improvement and rehabilitation of the lake, storm water treatment will preserve the natural systems and enhance the status of the recreational lake. According to our forecasts, based on literature data, the implementation of measures will allow for 2 years to significantly improve the water quality up to the standards that are acceptable to the competition world-class. It will also increase the aesthetic, natural and recreational value of the lake, return the historical significance of the lake as a favorite place rest of the townspeople. Designed rehabilitation project can be used in similar reservoirs, requiring the use of recreational activities.

\section{Acknowledgements}

This work was funded by the subsidy allocated to Kazan Federal University for the state assignment in the sphere of scientific activities.

\section{References}

Derevenskaya O.Yu., Mingazova N.M., Nabeeva E.G., Palagushkina O.V., Pavlova L.R., Barieva F.F. Ecological condition of lakes Boar in Kazan and the concept of recovery // Ecological Systems and Devices. № 9. 2012. - p. 20-25.

Derevenskaya O.Yu., Mingazova N.M. Nabeeva E.G., Palagushkina O.V., Pavlova L.R., Barieva F.F. The concept of biological rehabilitation of Lake Kaban in the Kazan city on the basis of monitoring condition // Ecological Systems and Devices. - № 3, 2011. - p. 3-9.

Derevenskaya O.Yu., Mingazova N. M., Mingaliev R.R., Pavlova L.R. Assessing economic losses of the small river ecosystems and developing of compensation measures within the framework of sports facilities construction // Mediterranean Journal of Social Sciences.- Vol. 5, № 18, 2014. - p. 345-348.

Method of calculating the cost of demolished green spaces and of compensatory planting. (Annex to Regulation №1 creation, maintenance and protection of green spaces in the municipality of Kazan), by order of 8.06.2006. № 2-9 - $100 \mathrm{p}$.

Procedure for determining the size of compensation for damage caused to land and vegetation approved by order of the Minister of Ecology and Natural Resources of the Republic of Tatarstan, April 8, 2002 № 314.

Rules for the creation, maintenance and protection of green spaces, approved by the Kazan City Duma on 08.06.2006, the № 2-9.

Temporary method of estimating the damage to fish stocks as a result of construction, renovation and expansion of enterprises, 
buildings and other objects and different types of work in fisheries waters ", approved by Ministry of Fisheries, Russian Federation Goskomekology, the Ministry of Finance of the USSR (Moscow, 1989) - 64 p.

The Federal Law "On Environmental Protection" of 10.01.2002 № 7-FZ.

The position on the assessment of planned economic and other activities on the environment in the Russian Federation (approved SCEP by order of 16.05.2000 № 372).

The Water Codex of the Russian Federation, № 74-FZ dated 06.02.2006. 